\title{
Interferência alelopática do chá de boldo-do-chile (Peumus boldus Molina, Monimiaceae) sobre sementes de alface e pepino
}

\author{
Allelopathic interference of boldo (Peumus boldus Molina, Monimiaceae) infusion on seeds of lettuce and \\ cucumber
}

\section{Antônio Marcos Oliveira Toledo*, Paulo Sergio Bordoni Ulguim, Selma dos Santos Kaeser e Fernando Teixeira Gomes}

Recebido em 16/04/2016 / Aceito em 22/06/2016

\section{RESUMO}

O boldo-do-chile é uma planta arbórea pertencente à família Monimiaceae. É utilizado pela população para diversas enfermidades e apresenta atividade bactericida, inseticida e alelopática. O objetivo deste estudo foi avaliar o potencial de atividade alelopática do chá de boldo-do-chile sobre a germinação e desenvolvimento inicial de sementes de alface e pepino. O bioensaio foi conduzido em laboratório sob temperatura ambiente, em delineamento inteiramente casualizado com cinco repetições. O chá de boldo-dochile foi adquirido no comércio local, preparado com água destilada fervente, diluído nas proporções de 25 , 50,75 e $100 \%$. Apenas água destilada foi utilizada para controle. A porcentagem de germinação, índice de velocidade de germinação e comprimento da raiz foram utilizados como parâmetros de avaliação alelopática. Para a porcentagem de germinação, foram verificados valores significativos na germinação de sementes de pepino no tratamento $100 \%$.A germinação de sementes de alface sofreu inibição total em todos os tratamentos com chá de boldo-do-chile. O índice de velocidade de germinação de sementes de pepino submetidas ao chá de boldo-do-chile sofreu influência significativa em todos os tratamentos em relação ao controle. As sementes de pepino submetidas ao chá de boldo-do-chile sofreram inibição no comprimento da raiz em todos os tratamentos avaliados, apresentando valores significativos em comparação ao controle. $\mathrm{O}$ chá de boldo-do-chile apresentou atividade alelopática sobre as sementes de alface e pepino, demonstrando a presença de moléculas bioativas que servem de subsídio para novos estudos.
PALAVRAS-CHAVE: bioatividade, controle, herbicida, plantas medicinais, produção vegetal.

\section{ABSTRACT}

Boldo (Peumus boldus Molina) is a tree of the Monimiaceae family. It is used by the people to treat several diseases, and presents diverse products such as: a bactericide, an insecticide and an allelopathy. The aim of this study was to evaluate the potential of the allelopatic activity of the boldo infusion on the germination and initial development of lettuce and cucumber seeds. The bioassay was conducted in an environmental temperature controlled laboratory, through a completely randomized design method with five repetitions. The boldo infusion was obtained in the local commerce, and prepared with boiling distillated water, diluted to the proportions of 25,50 , 75 , and $100 \%$. The control was only distillated water. The evaluation parameters used were germination percentage, germination speed index (measured each 24 hours) and root length (measured with a caliper rule on the last day of the experiment). Regarding germination percentage, we found significant values only using $100 \%$ treatment of cucumber seeds. The germination of lettuce seeds was inhibited throughout all of the treatments with boldo infusion. The germination speed index of cucumber seeds was influenced throughout all of the treatments. The root length of cucumber seeds was inhibited with all treatments and significantly different if compared with the control. Boldo infusion presented allelopathic activity on the seeds of lettuce and cucumber, showing the presence of bioactive molecules which can serve to subsidize new studies.

Laboratório de Fisiologia Vegetal - Centro de Ensino Superior de Juiz de Fora, Juiz de Fora, MG, Brasil.

*Autor para correspondência <antoniomarcosbio@live.com> 
KEYWORDS: bioactivity, control, herbicide, plant production, medicinal plants.

\section{INTRODUÇÃO}

As plantas produzem em seu metabolismo secundário, moléculas bioativas denominadas aleloquímicos, que são usados na forma de defesa contra $o$ ataque de microrganismos, insetos (MEDEIROS 1990, SOARES \& VIEIRA 2000), e também como garantia do sucesso ao competirem por nutrientes, luz, $\mathrm{CO}_{2}$ e água, sendo essa competição necessária para o estabelecimento no meio em que estão inseridas (SAMPIETRO 2001, GUREVITCH et al. 2009).

A liberação desses aleloquímicos ocorre por meio da volatilização, lixiviação, decomposição e exsudação (GUREVITCH et al. 2009), podendo interferir no ciclo de vida de outras espécies (MEDEIROS 1990, SOARES \& VIEIRA 2000), e também afetar os parâmetros qualitativos e quantitativos de culturas comerciais (BIANCHI 1995).

Em 1984, Rice denominou alelopatia como qualquer interferência direta ou indireta, danosa ou benéfica, que uma planta (incluindo microrganismos) exerce sobre a outra mediante compostos químicos liberados ao ambiente. A ação alelopática comprovada em espécies exóticas pode justificar o seu sucesso, alertando assim para cuidado especial a ser tomado no manejo das mesmas, uma vez que podem inibir o desenvolvimento de culturas adjacentes (OLIVEIRA et al. 2012). A alelopatia é utilizada para avaliar o efeito negativo ou positivo sobre espécies mais sensíveis como a alface (Lactuca sativa L.) e pepino (Cucumis sativus L.). Estas espécies são consideradas plantas testes, pois apresentam germinação rápida e uniforme, e um grau de sensibilidade que permite expressar os resultados sob baixas concentrações das substâncias alelopáticas (GABOR \& VEATCH 1981, FERREIRA \& AQUILA 2000).

O boldo-do-chile (Peumus boldus Molina) é uma planta arbórea pertencente à família Monimiaceae, nativo das regiões central e sul do Chile (LANHERS et al. 1991, STEFFEN 2010). Apresenta folhas acinzentadas, aromáticas e de gosto picante (ALONSO 1987). São utilizadas de várias formas pela população na forma de infusões, tinturas ou extratos para as mais variadas enfermidades, tais como: colagogo-colerético, diurético, digestivo, hepatoprotetor, analgésico, laxante, para dores de cabeça, congestão nasal, reumatismo, dor menstrual, vermífugo, sedativo e hipnótico (LANHERS et al. 1991, SPEISKY \& CASSELS 1994), além de apresentar atividade antifúngica (BITTNER et al. 2009, MENEZES \& LIMA 2013, SANTOS et al. 2014), inseticida (PÉREZ et al. 2007, GUERRA et al. 2009, BETANCUR et al. 2010), e alelopática (SOUZA et al. 2013).

Os componentes químicos encontrados no boldo-do-chile são alcaloides (boldina), taninos, esteroides, ácidos graxos, terpenos, flavonoides (quercetina e canferol), derivados flavônicos (boldosídio, peumosídio), eugenol e ascaridol (ALONSO 1987, PIETTA \& MAURI, 1988, VOGEL et al. 1999, MENDES et al. 2006, O'BRIEN et al. 2006, MORAIS et al. 2009). Outros autores registraram a presença de compostos fenólicos no chá de boldo-do-chile na emulsão de 1 sache a $250 \mathrm{~mL}$ de água por $10 \mathrm{~min}$. (LIMA et al. 2004, SCHWANZ et al. 2008).

$\mathrm{O}$ uso de agrotóxicos em lavouras e em áreas urbanas é prejudicial ao homem e ao meio ambiente. Desde 2010, o Brasil é considerado campeão no consumo de agrotóxicos, com uma média de mais de cinco quilos para cada brasileiro por ano (CARNEIRO et al. 2015). Dados do Programa de Análise de Resíduos de Agrotóxicos em Alimentos (PARA) da ANVISA permitem observar que $64 \%$ dos alimentos que chegam à mesa dos consumidores estão contaminados com produtos químicos (ANVISA 2013).

O uso contínuo de herbicidas pode gerar populações de plantas daninhas resistentes ou tolerantes, diminuindo a eficiência dos mesmos e agravando o problema de invasão (AGOSTINETTO et al. 2015). Vale ressaltar que o uso de substâncias químicas produzidas por plantas, pode auxiliar no controle de plantas daninhas em culturas de interesse agronômico, diminuindo a aplicação de produtos químicos e assim a contaminação do meio ambiente e de recursos naturais (GUSMAN et al. 2012).

O objetivo deste estudo foi avaliar o potencial de atividade alelopática do chá de boldo-do-chile sobre a germinação e desenvolvimento inicial de sementes de alface e pepino.

\section{MATERIAL E MÉTODOS}

O bioensaio foi conduzido no Laboratório de 
Fisiologia Vegetal do Centro de Ensino Superior de Juiz de Fora, Campus Arnaldo Janssen, Juiz de Fora, MG.

O chá de boldo-do-chile foi adquirido no comércio local, dissolvido em água destilada fervente, filtrado com o auxílio de um funil e papel filtro sobre um becker e, em seguida separados em elernmeyers $(100 \mathrm{~mL})$, para a preparação das concentrações de $100,75,50$ e $25 \%$. Os elernmeyers contendo as concentrações do chá quente foram vedados com plático filme PVC para evitar a perda de moléculas bioativas por evaporação. Para o grupo controle, foi utilizada água destilada.

Foram utilizadas 1000 sementes sendo 500 de pepino (C. sativus L.) e 500 de alface ( $L$. sativa L.). O bioensaio foi conduzido sobre uma bancada e lâmpadas fluorescentes foram mantidas acesas sobre o experimento, durante o período de 72 horas (SOARES \& VIEIRA 2000). Adotou-se o delineamento inteiramente casualizado com cinco repetições, montado em placas de Petri de 9,5 cm forradas com dois papéis filtro e umidecidas com $5 \mathrm{ml}$ do chá, equivalente a cada tratamento.

Cada placa de Petri recebeu 20 sementes, e foram mantidas no laboratório sobre temperatura ambiente e com fotoperíodo de 24 horas. A temperatura média durante o experimento foi de $25,3{ }^{\circ} \mathrm{C}$ e a umidade relativa do ar 73,33\%, ambas foram aferidas a cada 24 horas com o auxílio de um termômetro digital.

Os parâmetros utilizados para avaliação da alelopatia foram: porcentagem de germinação, índice de velocidade de germinação e comprimento da raiz. A porcentagem de germinação e o índice de velocidade de germinação foram mensurados a cada 24 horas, considerando-se germinadas as sementes que apresentaram comprimento radicular de no mínimo 2 $\mathrm{mm}$. O comprimento da raiz foi mensurado com um paquímetro manual no último dia de avaliação do experimento (72 horas).

Para o cálculo do índice de velocidade de germinação, utilizou-se a fórmula: IVG $=[\mathrm{N} 1 / 1+$ $\mathrm{N} 2 / 2+\mathrm{N} 3 / 3+\ldots \mathrm{Nn} / \mathrm{n}]$ x 100 , onde $\mathrm{N}$ é o número de sementes germinadas e $\mathrm{n}$ o número de dias da semeadura, sugerido por WARDLE et al. (1991).

Os dados porcentagem de germinação e comprimento da raiz foram submetidos ao teste ANOVA e comparados pelo teste $t$ student $(\mathrm{p}<0,05)$, usando o pragrama computacional software estatístico BioEstat 5.0 (AYRES et al. 2007).

\section{RESULTADOS E DISCUSSÃO}

Os resultados obtidos neste trabalho mostram que o chá de boldo-do-chile apresentou fitotoxidade para as sementes de pepino e alface em todos os tratamentos avaliados. A porcentagem de germinação de sementes de pepino submetidas ao chá de boldodo-chile para os tratamentos 25,50 e $75 \%$ não foram verificados valores significativos em relação ao tratamento controle, enquanto que o tratamento $100 \%$ apresentou valor significativo $(\mathrm{p}<0,01)$ quando comparado ao tratamento controle e tratamento $25 \%$. $\mathrm{O}$ decréscimo na porcentagem de germinação das sementes de pepino se deu a partir do tratamento $50 \%$, chegando a ser maior no tratamento $100 \%$. Os tratamentos 50 e $75 \%$ não foram significativos em relação ao tratamento de 100\% (Figura 1).

O chá de boldo-do-chile inibiu totalmente a germinação de sementes de alface em todos os tratamentos avaliados, impedindo a avaliação dos demais parâmetros (Figura 1).

Plantas medicinais podem inibir ou estimular a germinação e o desenvolvimento de sementes cultiváveis de forma significativa. Estudos mostraram que os extratos aquosos de capuchinho, pariparoba, hortelã pimenta, pata-de-vaca, favia, salvia-da-gripe, terramicina e pinus, inibiram totalmente a germinação de sementes de alface (MAIRESSE et al. 2007), corroborando os resultados encontrados neste trabalho para a porcentagem de germinação de sementes de alface submetidas a diferentes tratamentos do chá de boldo-do-chile.

O boldo-do-chile teve influência significativa na germinação de sementes de alface, sendo que o mesmo não interferiu na germinação de sementes de tomate (SOUZA et al. 2013). No entanto, o extrato do falso-boldo (Coleus barbatus (A.) Benth.) não influenciou de forma significativa a germinação de sementes de alface (MAIRESSE et al. 2007). Por outro lado, à concentração de $30 \%$ do extrato aquoso de folhas frescas do falso-boldo coletadas no inverno, influenciou de forma negativa a germinação de sementes de alface, diferindo das sementes tratadas com extratos de folhas coletadas em outras estações do ano (PELEGRINI \& CRUZ-SILVA 2012).

A germinação de sementes de repolho, brócolis, couve, alface, rúcula, tomate e mostarda foi inibida a partir das concentrações de $50 \%$ do extrato de falsoboldo (GUSMAN et al. 2012). Estes resultados são semelhantes aos encontrados neste ensaio para a 


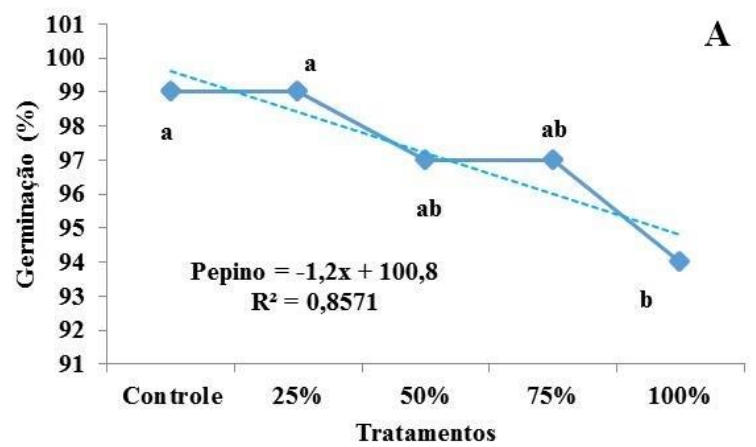

Figura 1 - Germinação de sementes de pepino (A) concentrações $0,25,50,75$ e $100 \%$.

Figure 1 - Germination of cucumber (A) and lettuce (B) seeds treated with boldo infusion at concentrations of $0,25,50,75$ and $100 \%$.

germinação das sementes de alface (a partir de $25 \%$ ) e pepino (a partir de 50\%) tratadas com chá de boldodo-chile. A resistência ou tolerância aos metabólitos secundários é uma característica inerente à espécie, existindo aquelas mais sensíveis, como alface, tomate e o pepino (FERREIRA \& AQUILA 2000).

O chá de boldo (Coleus sp.) e hortelã (Mentha sp.), não influenciaram a germinação de sementes de alface (OLIVEIRA et al. 2012), diferindo dos resultados encontrados neste trabalho para a germinação de sementes de alface tratadas com chá de boldo-do-chile. Isso sugere que chás tradicionais também podem influenciar na germinação de sementes, atuando como uma forma alternativa ao controle de plantas daninhas.

A germinação de sementes de cebola (Allium cepa L.), sofreu influência positiva e negativa quando submetidas ao tratamento com três espécies diferentes de boldo (IGANCI et al. 2006). O decréscimo na porcentagem de germinação de sementes de alface e picão-preto (Bidens pilosa L.) se dá de acordo com o aumento das concentrações de boldo-de-jardim (Plectranthus barbatus Andrews) (AZAMBUJA et al. 2010), diferenciando dos resultados encontrados neste estudo para o efeito do boldo-do-chile sobre as sementes de pepino.

Comparando os tratamentos do pepino com os de alface submetidos ao chá, verificou-se que houve diferença significativa $(p<0,0001)$ entre eles em todos os tratamentos avaliados (Tabela 1). Isso mostra que as sementes de alface são mais sensíveis ao boldo-do-chile em comparação com sementes de pepino, sugerindo que novos experimentos com concentrações mais baixas sejam realizados com o intuito de encontrar uma concentração menos tóxica para estas sementes.

O extrato aquoso de folhas de Emilia sonchifolia (L.) DC. inibiu de forma significativa a germinação de sementes de sorgo (Sorghum bicolor L.), pepino e da planta daninha picãopreto (OLIVEIRA et al. 2011). Extratos de carurú (Amaranthus retroflexus L.) nas concentrações de 5 e $10 \%$ não influenciaram a germinação de sementes de pepino (BAKHSHAYESHAN-AGDAM et al. 2015).

De acordo com GORLA \& PEREZ (1977), a germinação de sementes de pepino sofreu interferência alelopática apenas nas concentrações de 75 e 100\% do extrato de Lanata camara L., enquanto os extratos de Miconia albicans (Sw.) Triana, Leucaena leucocephala (Lam) de Wit e Drymis winteri Forst não influenciam na sua germinalidade, diferindo dos resultados encontrados para os tratamentos 75 e $100 \%$ do chá de boldo-do-chile.

O efeito fitotóxico demonstrado pela redução da germinação de sementes de alface sugere que a reserva nutritiva foi provavelmente afetada, influenciando diretamente a emissão do eixo radícula-epicótilo (AZAMBUJA et al. 2010). Sendo assim, presume-se que a alteração na germinação de sementes, se dá pela alteração na permeabilidade das membranas, na transcrição e tradução do DNA, na conformação das enzimas e receptores, ou ainda, pela combinação desses fatores no processo de germinação das sementes (FERREIRA \& AQUILA 2000, PESSOTTO \& PASTORINI 2007).

Com relação ao índice de velocidade de germinação, observou-se que houve influência do chá de boldo-do-chile sobre as sementes de pepino. $\mathrm{O}$ menor índice de velocidade de germinação foi registrado para o tratamento $75 \%(5,24)$, seguido 
Tabela 1 - Média e desvio padrão da porcentagem de germinação de sementes de pepino e alface submetidas a diferentes tratamentos do chá de boldo-do-chile.

Table 1 - Mean and standard deviation of germination percentage of cucumber and lettuce seeds submitted to different treatments of boldo infusion.

\begin{tabular}{lcc}
\hline \multicolumn{3}{c}{$\mathrm{X} \pm \mathrm{DP}$} \\
\hline Tratamentos & Pepino & Alface \\
Controle & $0,99 \pm 0,10 \mathrm{aA}$ & $0,72 \pm 0,31 \mathrm{aB}$ \\
$25 \%$ & $0,99 \pm 0,17 \mathrm{aA}$ & $0,00 \pm 0,00 \mathrm{bB}$ \\
$50 \%$ & $0,97 \pm 0,17 \mathrm{abA}$ & $0,00 \pm 0,00 \mathrm{bB}$ \\
$75 \%$ & $0,97 \pm 0,24 \mathrm{abA}$ & $0,00 \pm 0,00 \mathrm{bB}$ \\
$100 \%$ & $0,94 \pm 0,45 \mathrm{bA}$ & $0,00 \pm 0,00 \mathrm{bB}$ \\
\hline
\end{tabular}

Médias seguidas da mesma letra minúscula, nas linhas, e da mesma letra maiúscula, nas colunas, não diferem entre si pelo teste $\mathrm{t}(\mathrm{p}<0,05)$.

dos tratamentos $100(5,32), 50(5,33)$ e $25 \%(5,50)$ em relação ao controle $(6,15)$ (Figura 2). O baixo índice de velocidade de germinação para as sementes tratadas com chá de boldo-do-chile se deu devido à germinação ter iniciado no segundo dia, enquanto que as sementes do grupo controle iniciaram nas primeiras 24 horas do experimento, indicando a influência dos aleloquímicos presentes no chá na velocidade de germinação das sementes.

Embora a porcentagem de germinação das sementes de pepino tenham sido altas, o índice de velocidade de germinação mostra que o chá de boldodo-chile tem efeito inibitório sobre sementes de pepino.

Outros pesquisadores relatam a interferência de extratos botânicos de aveia, feijão-guandu, azevém e braquiária (DALAZEN CASTAGNARA et al. 2012), barbatimão (BARREIRO et al. 2005), L. camara, M. albicans e D. winteri (GORLA \& PEREZ 1977) sobre o índice de velocidade de germinação de sementes de pepino.

O decréscimo do índice de velocidade de germinação de acordo com o aumento das concentrações, também foi observado por PELEGRINI \& CRUZ-SILVA (2012) ao avaliarem o efeito alelopático de falso-boldo sobre sementes de alface.

A atividade alelopática de alguns compostos está relacionada à concentração testada, ou seja, altas concentrações podem inibir a germinação, mas por outro lado, concentrações mais baixas podem estimular o desenvolvimento (RICE 1984, AOKI et al. 1997, GATTI et al. 2004). Com isso, sugere-se que a velocidade de germinação das sementes de pepino possa estar relacionada com a concentração do chá de boldo-do-chile.
Comparando os tratamentos do chá de boldodo-chile com o controle, observa-se redução no comprimento da raiz do pepino expostas ao chá em todos os tratamentos. As médias dos tratamentos 25, 50,75 e $100 \%$ foram significativas $(p<0,01)$ em relação ao controle, sendo registrada a maior interferência no crescimento para o tratamento $100 \%$ (Figura $3)$. Os tratamentos 25 e $50 \%$ apresentaram valores significativos em relação aos demais tratamentos do chá de boldo-do-chile e ao controle. Em relação aos tratamentos 75 e 100\%, ambas não diferem entre si (Figura 3). O comprimento da raiz é um bom parâmetro para avaliar a influência alelopática de diferentes concentrações dos extratos sobre o desenvolvimento inicial de sementes (GORLA \& PEREZ 1977).

Para ambos os tratamentos com chá de boldo-do-chile sobre as sementes de pepino, foi observado inibição no crescimento da raiz primária, e ausência significativa do desenvolvimento de raízes secundárias, diferente do desenvolvimento normal encontrado no tratamento controle. Nos tratamentos 75 e $100 \%$, a germinação das sementes foi seguida da alteração na coloração e inibição do desenvolvimento da raiz.

A alteração morfológica da raiz também foi observada por outros autores (MARASCHIN-SILVA \&AQUILA2006, AIRES 2007, GUSMAN etal.2008), indicando mais uma influência dos aleloquímicos no desenvolvimento inicial das plântulas. A avaliação das variações morfológicas é um instrumento valioso nos experimentos de alelopatia (FERREIRA \& AQUILA 2000), sendo a raiz mais sensível que a germinação das sementes.

O desenvolvimento das sementes de alface sofreram ação alelopática do extrato de boldo-dochile (SOUZA et al. 2013), corroborando os resultados 


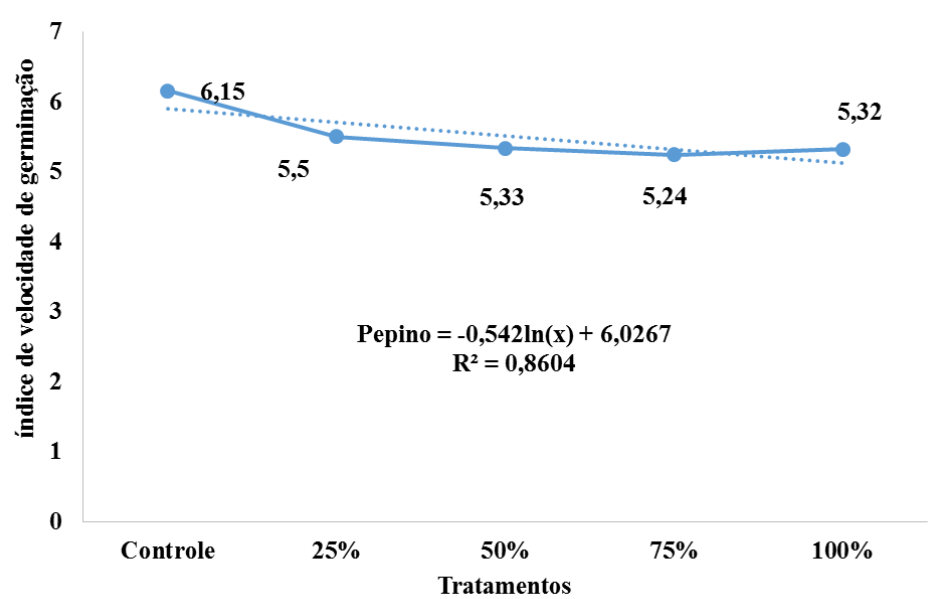

Figura 2 - Índice de velocidade de germinação de sementes de pepino submetidas a diferentes tratamentos do chá de boldo-do-chile durante o período de 72 horas.

Figure 2 - Index of germination velocity of seeds of cucumber submitted to different treatments of boldo infusion during a 72 hour period.

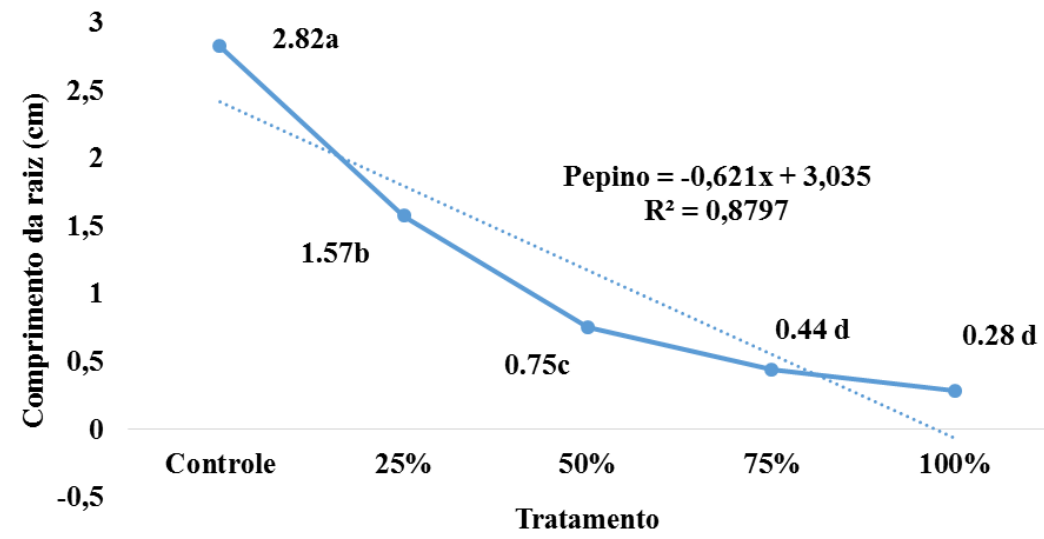

Figura 3 - Média do comprimento da raiz $(\mathrm{cm})$ de plântulas de pepino crescidas sobre papel filtro nos diferentes tratamentos do chá de boldo-do-chile no período de 72 horas.

Figure 3 - Mean length of root $(\mathrm{cm})$ of cucumber seedlings growing on filter paper in different treatments of boldo infusion in a period of 72 hours.

Médias seguidas de letras diferentes diferem entre si pelo teste $t$ stundent $(\mathrm{p}<0,05)$.

encontrados neste trabalho para as sementes de alface e pepino. IGANCI et al. (2006) verificaram que o extrato de três tipos de boldo pode ou não estimular o crescimento da radícula e divisão celular de raízes de cebola.

BELINELO et al. (2008) encontraram baixa taxa de crescimento da raiz de sorgo e pepino no extrato etanólico de Arctium minus (Hill) Bernh. PESSOTTO \& PASTORINI (2007) encontraram efeito alelopático (negativo e positivo) do extrato de funcho (Foeniculum vulgare Mill.) sobre o crescimento radicular de sementes de alface e tomate em diferentes concentrações.

Os extratos aquosos de falso-boldo e alecrim inibem, enquanto os de manjericão e manjerona estimulam o crescimento da parte aérea e raiz do meloeiro (DORNELES et al. 2015).

Espécies vegetais podem ser utilizadas em cobertura vegetal com a finalidade de induzir o não desenvolvimento de plantas indesejáveis, minimizando o uso de herbicidas, além de proteger e melhorar as condições físicas, químicas e biológicas do solo (CORSATO et al. 2008). Com isso, torna-se importante o estudo do efeito alelopático do chá de boldo-do-chile em plantas daninhas. 


\section{CONCLUSÃO}

O chá de boldo-do-chile apresentou atividade alelopática sobre as sementes de pepino e alface, demonstrando a presença de moléculas bioativas no chá e a necessidade de novos estudos com concentrações mais baixas.

A alteração morfológica da raiz é um parâmetro para a avaliação do efeito alelopático em sementes de pepino, uma vez que o crescimento radicular apresenta ser mais sensível do que a germinação das sementes.

\section{REFERÊNCIAS}

AGOSTINETTO D et al. 2015. Manejo e controle de plantas daninhas. In: ALUÍZIO B \& SCHEEREN PL. Trigo do plantio a colheita. 1.ed. Viçosa. p.169-184.

AIRES SS. 2007. Potencial alelopático de espécies nativas do cerrado na germinação e desenvolvimento inicial de invasoras. Dissertação (Mestrado em Botânica). Brasília: UnB. 61p.

ALONSO JR. 1987. Tratado de Fitomedicina: Bases clínicas e farmacológicas. Curitiba: Scientia et Labor. 42p. ANVISA - AGÊNCIA NACIONAL DE VIGILÂNCIA SANITÁRIA. 2013. Programa de Análise de Resíduos de Agrotóxicos em Alimentos (PARA): relatório de atividades de 2011 e de 2012. Brasília. p.44.

AOKI T et al. 1997. Biologically active cleredone-type diterpene glycosides from the root - stalks of Dicranopteris pedata. Phytochemistry 46:839-844

AZAMBUJA N et al. 2010. Potencial alelopático de Plectranthus barbatus Andrews na germinação de sementes de Lactuca sativa L. e de Bidens pilosa L. Revista de Ciências Agroveterinárias 9:66-73.

AYRES M et al. 2007. BioEstat 5.0: aplicações Estatísticas nas Áreas das Ciências Biológicas e Médicas. $5^{\text {th }}$ ed. Instituto de Desenvolvimento Sustentável Mamirauá IDSM/MCT/CNPq, Belém. 364p.

BAKHSHAYESHAN-AGDAM H et al. 2015. Allelopathic effects of redroot pigweed (Amaranthus retroflexus L.) on germination $\&$ growth of cucumber, alfafa, common bean and bread wheat. Acta Agriculturae Slovenica 105:193202.

BARREIRO AP et al. 2005. Efeito alelopático de extratos de parte aérea de barbatimão (Stryphnodendron adstringens (Mart.) Coville) na germinação e desenvolvimento da plântula de pepino. Revista Brasileira de Plantas Medicinais 8:4-8.

BELINELO VJ et al. 2008. Alelopatia de Arctium minus Bernh (Asteraceae) na germinação e crescimento radicular de sorgo e pepino. Revista Caatinga 21:12-16.

BETANCUR RJ et al. 2010. Insecticidal activity of Peumus boldus Molina essential oil against Sitophilus zeamais Motschulsky. Chilean Journal of Agricultural Research
70:399-407.

BIANCHI MA. 1995. Programa de difusão do manejo integrado de plantas daninhas em soja no Rio Grande do Sul: 1994/95. Cruz Alta: FUNDACEP FECOTRIGO 31p. BITTNER M et al. 2009. Fungistatic activity of essential oils extracted from Peumus boldus Mol. Laureliopsis philippiana (Looser) Schodde and Laurelia sempervirens (Ruiz \& Pav.) Tul. (Chilean Monimiaceae). Chilean Journal of Agricultural Research 69:30-37.

CARNEIRO FF et al. (Org.). 2015. Dossiê ABRASCO: um alerta sobre os impactos dos agrotóxicos na saúde. Rio de Janeiro: EPSJV; São Paulo: Expressão Popular 624p.

CORSATO JM et al. 2008. Efeito alelopático do tremoço branco (Lupinus albus L.) sobre a germinação e o crescimento inicial da alface, soja, picão-preto. Revista Brasileira de Biociências 6:14-15.

DALAZEN CASTAGNARA D et al. 2012. Potencial alelopático de aveia, feijão guandu, azevém e braquiária na germinação de sementes e atividade enzimática do pepino. Ensaios e Ciência: Ciências Biológicas, Agrárias e da Saúde 16:31-42.

DORNELES KR et al. 2015. Efeito alelopático de extratos de plantas medicinais e condimentares em meloeiro (Cucumis melo L.). Ciência e Natura 37:212-217.

FERREIRA GF \& AQUILA MEA. 2000. Alelopatia: Uma área emergente da ecofisiologia. Revista Brasileira de Fisiologia Vegetal 12:175-204.

GABOR WE \& VEATCH C. 1981. Isolation of phytotoxin from quackgrass (Agropyon repens) rhizomes. Weed Science 29:155-159.

GATTI AB et al. 2004. Atividade alelopática de extratos aquosos de Aristolochia esperanzae O. Kuntze na germinação e no crescimento de Lactuca sativa L. e Raphanus sativus L. Acta Botânica Brasilica 18:459-472. GORLA CM \& PEREZ SCJGA. 1977. Influência de extratos aquosos de folhas de Miconia albicans Triana, Lantana camara L., Leucaena leucocephala (Lam) de Wit e Drimys winteri Forst, na germinação e crescimento inicial de sementes de tomate e pepino. Revista Brasileira de Sementes 19:261-266.

GUERRA AMNM et al. 2009. Atividade inseticida de plantas medicinais sobre o Callosobruchus maculatus (Coleoptera: Bruchidae). Revista Caatinga 22:146-150.

GUSMAN GS et al. 2008. Alelopatia de Baccharis dracunculifolia DC. sobre a germinação e desenvolvimento de espécies cultivadas. Acta Scientiarum Biological Sciences 30:119-125.

GUSMAN GS et al. 2012. Alelopatia de espécies vegetais com importância farmacêutica para espécies cultivadas. Biotemas 25:37-48.

GUREVITCH J et al. 2009. Ecologia Vegetal. 2.ed. Porto Alegre. 540p.

IGANCI JRV et al. 2006. Efeito do extrato aquoso de diferentes espécies de boldo sobre a germinação e índice mitótico de Allium cepa L. Arquivos do Instituto Biológico 
73:79-82.

LANHERS MC et al. 1991. Hepatoprotective and antiInflammatory effects of a traditional medicinal plant of Chile, Peumus boldus. Planta Medica 57:110-115.

LIMA VLAG et al. 2004. Nota Prévia: Teor de Compostos Fenólicos Totais em Chás Brasileiros. Brazilian Journal of Food Technology 7:187-190.

MAIRESSE LAS et al. 2007. Bioatividade de extratos vegetais sobre alface (Lactuca sativa). Revista da Faculdade de Zootecnia, Veterinária e Agronomia 14:1-12.

MARASCHIN-SILVA F \& AQUILA MEA. 2006.

Potencial alelopático de espécies nativas na germinação e crescimento inicial de Lactuca sativa L. (Asteraceae). Acta Botânica Brasilis 20:61-69.

MEDEIROS ARM. 1990. Alelopatia: importância e suas aplicações. Horti Sul 1:27-32.

MENDES BG et al. 2006. Triagem de glicolipídios em plantas medicinais. Revista Brasileira de Farmacognosia 16:568-575.

MENEZES CP \& LIMA EO. 2013. Atividade antifúngica de óleos essenciais sobre cepas de Cladosporium carrionii. Revista Brasileira de Farmácia 94:49-53.

MORAIS SM et al. 2009. Ação antioxidante de chás e condimentos de grande consumo no Brasil. Revista Brasileira de Farmacognosia 19:315-320.

O'BRIEN PO et al. 2006. Boldine and its antioxidante or health-promoting properties. Chemical-Biological Interactions 159:1-17.

OLIVEIRA EP et al. 2012. Determinação do efeito alelopático, índice mitótico e utilização do boldo, capimcidreira e hortelã no bairro Boa Vista em Mandaguari (PR). Diálogos \& Saberes 8:41-53.

OLIVEIRA LGA. 2011. Alelopatia de Emilia sonchifolia (1.) DC. (Asteraceae) na germinação e crescimento inicial de sorgo, pepino e picão-preto. Enciclopédia Biosfera 7:110.

PELEGRINI LL \& CRUZ-SILVA CTA. 2012. Variação sazonal na alelopatia de extratos aquosos de Coleus barbatus (A.) Benth. sobre a germinação e o desenvolvimento de Lactuca sativa L. Revista Brasileira de Plantas Medicinais 14:376-382.

PÉREZ F et al. 2007. Variación anual de las propiedades insecticidas de Peumus boldus sobre Sitophilus zeamais. Pesquisa Agropecuária Brasileira 42:633-639.

PESSOTTO GP \& PASTORINI LH. 2007. Análise da germinação de alface (Lactuca sativa L.) e tomate (Lycopersicon esculentum Mill.) sob a influência alelopática do funcho (Foeniculum vulgare Mill.). Revista Brasileira de Biociências 5:990-992.

PIETTAP \& MAURI P. 1988. Determination of isoquinoline alkaloids from Peumus boldus by high-performance liquid chromatography. Journal of Chromatography 457:442-445. RICE EL. 1984. Allelopathy. 2.ed. Orlando: Academic Press Inc. 422p.

SAMPIETRO DA. 2001. Alelopatía: concepto, características, metodología de estudio e importância. Disponível em: http:/www.produccion-animal.com. ar/produccion_y_manejo_pasturas/pasturas $\% 20$ artificiales/19-alelopatia.pdf. Acesso em: 23 set. 2015.

SANTOS CZ et al. 2014. Avaliação da atividade antifúngica do óleo essencial de Peumus boldus (Monimiaceae) frente à levedura da espécie Candida albicans. Visão Acadêmica 15:43-50.

SCHWANZ M et al. 2008. Análise de metais pesados em amostras de Peumus boldus Mol. (Monimiaceae). Revista Brasileira de Farmacognosia 18:98-101.

SOARES GLG \& VIEIRA TR. 2000. Inibição da germinação e do crescimento radicular de alface (cv. "Grand Rapids") por extratos aquoso de cinco espécies de Gleicheniaceae. Floresta e Ambiente 7:180-197.

SOUZAAS et al.2013. Análise comparativa da sensibilidade de sementes de Lactuca sativa L. e Lycopersicon esculentum Mill. submetidas aos tratamentos com plantas medicinais. Revista Biologia e Farmácia 9:26-33.

SPEISKY H \& CASSELS BK. 1994. Boldo and boldine: an emerging case of natural drug development. Pharmacological Research 29:1-10.

STEFFEN PCJ. 2010. Plantas Medicinais - Usos populares tradicionais. Instituto de Pesquisas/UNISINOS 74p.

VOGEL $\mathrm{H}$ et al. 1999. Studies of genetic variation of essential oil and alkaloid content in boldo (Peumus boldus). Planta Medica 65:90-91.

WARDLE DA et al. 1991. Allelopathy influence of nodding thistle (Carduus nutans L.) seeds on germination and radicle growth of pasture plants. New Zealand Journal of Agricultural Research 34:185-191. 